\title{
CUI@IUI: Theoretical and Methodological Challenges in Intelligent Conversational User Interface Interactions
}

\author{
Philip R. Doyle \\ University College Dublin \\ philip.doyle1@ucdconnect.ie \\ Benjamin R. Cowan \\ University College Dublin \\ benjamin.cowan@ucd.ie \\ Stephan Schlögl \\ Management Center Innsbruck \\ stephan.schloegl@mci.edu \\ Christine Murad \\ University of Toronto \\ cmurad@taglab.ca
}

\author{
Daniel Rough \\ University of Dundee \\ drough001@dundee.ac.uk \\ Leigh Clark \\ Swansea University \\ l.m.h.clark@swansea.ac.uk \\ María Inés Torres \\ Universidad del Pais Vasco \\ manes.torres@ehu.eus \\ Matthew Aylett \\ CereProc Ltd. \\ matthewa@cereproc.com
}

\author{
Justin Edwards \\ University College Dublin \\ justin.edwards@ucdconnect.ie \\ Martin Porcheron \\ Swansea University \\ m.a.w.porcheron@swansea.ac.uk \\ Cosmin Munteanu \\ University of Toronto Mississauga \\ cosmin.munteanu@utoronto.ca \\ Heloisa Candello \\ IBM Research Brazil \\ heloisacandello@br.ibm.com
}

\author{
Jaisie Sin \\ University of Toronto \\ js.sin@mail.utoronto.ca
}

\author{
Minha Lee \\ Eindhoven University of Technology \\ m.lee@tue.nl
}

\begin{abstract}
This workshop aims to bring together the Intelligent User Interface (IUI) and Conversational User Interface (CUI) communities to understand the theoretical and methodological challenges in designing, deploying and evaluating CUIs. CUIs have continued to prosper with the increased use and technological developments in both text-based chatbots and speech-based systems. However, challenges remain in creating established theoretical and methodological approaches for CUIs, and how these can be used with recent engineering advances. These include assessing the impact of interface design on user behaviours and perceptions, developing design guidelines, understanding the role of personalisation and issues of ethics and privacy. Our half-day multidisciplinary workshop brings together researchers and practitioners from the IUI and CUI communities in academia and industry. We aim to (1) identify and map out key focus areas and research challenges to address these critical theoretical and methodological gaps and (2) foster strong relationships between disciplines within and related to Artificial Intelligence (AI) and Human-Computer Interaction (HCI).
\end{abstract}

\section{CCS CONCEPTS}

• Human-centered computing $\rightarrow$ Natural language interfaces.

Permission to make digital or hard copies of all or part of this work for personal or classroom use is granted without fee provided that copies are not made or distributed for profit or commercial advantage and that copies bear this notice and the full citation on the first page. Copyrights for components of this work owned by others than ACM must be honored. Abstracting with credit is permitted. To copy otherwise, or republish, to post on servers or to redistribute to lists, requires prior specific permission and/or a fee. Request permissions from permissions@acm.org.

IUI '20, April 13-17, 2020, Texas, USA

(C) 2020 Association for Computing Machinery.

ACM ISBN 978-1-4503-XXXX-X/18/06 ..\$15.00

https://doi.org/10.1145/1122445.1122456

\section{INTRODUCTION}

This half-day multidisciplinary workshop aims to bring members of the CUI and IUI communities together to critically map out and understand theoretical and methodological gaps in designing and evaluating CUIs. In bringing together researchers from industry and a diverse range of academic disciplines in $\mathrm{AI}, \mathrm{HCI}$ and beyond, we hope to establish new directions and paradigms for an increasingly common means of interactions with machines. The technological advancements and rapid growth of commercially available chatbots [6] and speech interfaces [5] - accessible through websites, mobile devices, in-car communication systems and smart speakers amongst others - makes the need for developing established theoretical and methodological frameworks in CUI interactions critical [5]. By working on these problems together across disciplines, we hope to build a cohesive, diverse community of researchers with an interest in exploring theoretical and methodological issues in the field.

\section{PREVIOUS HISTORY}

While there is a trend towards investigating conversational user interface interaction in the IUI community, e.g., [7, 9], the topic has not yet been a central point of interest. As such, hosting a CUI workshop at IUI presents an opportunity for creating new cross-disciplinary collaborations and for growing interest in this topic in both communities. Given the focus of IUI on AI and HCI, we consider it an ideal venue for a workshop at the heart of this intersection: intelligent conversational user interface interactions. This workshop builds on the two successful ACM SIGCHI In-Cooperation international Conferences on Conversational User Interfaces (CUI) held in Dublin in 2019 [1] and virtually via Bilbao in 2020 [2]. Additionally, we draw experience from recent workshops focused on collaboration 
and social computing [8], grand challenges [3] and theoretical and methodological perspectives in $\mathrm{HCI}$ [4].

\section{ORGANISERS AND COMMITTEE}

The key organisers are listed as authors of this proposal, many of whom are part of the CUI Steering Committee (2019-2021). Over previous years, we have been privileged to benefit from a vibrant and energetic community eager to volunteer in taking on program committee roles for our conferences and workshops. We are extremely confident that we can continue to do so should this workshop be accepted for IUI 2021. For more information visit the workshop website (http://www.speech-interaction.org/CSCW2020/organisers.html)

\section{PARTICIPANTS}

Our workshop aims to bring together 20-25 world-leading researchers and industry representatives from a broad range of communities related to speech, dialogue, human-machine interaction, speech interface design and voice user experience. We aim to highlight the importance of a multidisciplinary approach to solving issues related to CUI interactions, broadening the reach of speech interface work at IUI and within HCI in general to other research communities (e.g. speech technology, linguistics, dialogue research, cognitive sciences). Further, we also seek to build a collaborative, diverse and cross-disciplinary conversational interaction community that is strongly connected to IUI and AI-related disciplines.

With over 60 delegates attending CUI 2019, over 100 attending CUI 2020 (an online event due to COVID-19), and regular attendances of 25 to 30 people at our workshop events, we are confident that the proposed workshop will attract similar levels of interest at IUI. We will continue championing this research space, by inviting participants through the usual channels (i.e. conference announcements, social media, mailing lists) as well as hosting a dedicated website for the workshop.

\section{WORKSHOP FORMAT}

We propose a hybrid workshop/mini-conference model. We will invite submissions of 2-page short papers (similar to IUI late-breaking work) as well as original long papers (6-10 pages), with both categories being independently reviewed by three reviewers. Successful authors will be invited to expand on their work for submission to the next CUI conference. We will also invite the submission of a short abstract or position statements for participants who wish to join the workshop without submitting a paper. At previous events, we have found this option to be particularly attractive to industrybased researchers.

In addition to being a successful model in previous workshops and events, our experience from CUI 2020 and CUI@CHI 2020 suggests a half-day workshop, following the structure outlined, is ideal should we need to switch to a virtual format. The structure and length will stay the same whether held in-person or online (see below), whilst limiting the event to a half day means that, should a virtual workshop be necessary, we can reduce the risk of fatigue and better accommodate attendees in different time zones. The workshop will be structured as follows (times approximate):

- Introductions (30 minutes)
- Paper Presentations (1.5 hours)

- Short Provocation Pieces or Position Statements (40 minutes)

- Break-out sessions to discuss presented works and provocations (chaired by our volunteers) (45 minutes)

- A short break (30 minutes)

- Group discussion regarding next steps for the community (hosted by workshop chairs) (1 hour)

\section{PLANNED OUTCOMES}

Following the workshop, our aims are to:

(1) Organise further workshops on topics relevant to intelligent conversational user interface interaction. This will include targeting INTERSPEECH, SIGDIAL, CogSci, AutoUI, CHI, and IUI conferences, as well as identifying further collaborative opportunities across disciplines.

(2) Draw upon the results of breakout sessions and group discussion to propose key research directions for community members, and identify potential collaborative projects.

(3) Connect and foster the community of research and development between CUI and IUI researchers and industry partners

\section{ACKNOWLEDGMENTS}

This work is supported by the Irish Research Council Enterprise Partnership Scheme and Voysis Ltd (R17830), as well as the Science Foundation Ireland ADAPT Centre (13/RC/2106).

\section{REFERENCES}

[1] 2019. CUI '19: Proceedings of the 1st International Conference on Conversational User Interfaces (Dublin, Ireland). ACM, New York, NY, USA.

[2] 2020. CUI '20: Proceedings of the 2nd Conference on Conversational User Interfaces (Bilbao, Spain). ACM, New York, NY, USA

[3] Heloisa Candello, Cosmin Munteanu, Leigh Clark, Jaisie Sin, María Inés Torres, Martin Porcheron, Chelsea M. Myers, Benjamin Cowan, Joel Fischer, Stephan Schlögl, Christine Murad, and Stuart Reeves. 2020. CUI@CHI: Mapping Grand Challenges for the Conversational User Interface Community. In Extended $A b$ stracts of the 2020 CHI Conference on Human Factors in Computing Systems (Honolulu, HI, USA) (CHI EA '20). ACM, New York, NY, USA, 1-8. https: //doi.org/10.1145/3334480.3375152

[4] Leigh Clark, Benjamin R Cowan, Justin Edwards, Cosmin Munteanu, Christine Murad, Matthew Aylett, Roger K Moore, Jens Edlund, Eva Szekely, Patrick Healey, et al. 2019. Mapping Theoretical and Methodological Perspectives for Understanding Speech Interface Interactions. In Extended Abstracts of the 2019 CHI Conference on Human Factors in Computing Systems. 1-8.

[5] Leigh Clark, Philip Doyle, Diego Garaialde, Emer Gilmartin, Stephan Schlögl, Jens Edlund, Matthew Aylett, João Cabral, Cosmin Munteanu, Justin Edwards, et al. 2019. The State of Speech in HCI: Trends, Themes and Challenges. Interacting with Computers 31, 4 (2019), 349-371. https://doi.org/10.1093/iwc/iwz016

[6] Asbjørn Følstad and Petter Bae Brandtzæg. 2017. Chatbots and the new world of HCI. interactions 24, 4 (2017), 38-42.

[7] Xu Han. 2020. Am I Asking It Properly? Designing and Evaluating Interview Chatbots to Improve Elicitation in an Ethical Way. In Proceedings of the 25th International Conference on Intelligent User Interfaces Companion (Cagliari, Italy) (IUI '20). Association for Computing Machinery, New York, NY, USA, 33-34. https: //doi.org/10.1145/3379336.3381509

[8] Martin Porcheron, Leigh Clark, Matt Jones, Heloisa Candello, Benjamin R. Cowan, Christine Murad, Jaisie Sin, Matthew P. Aylett, Minha Lee, Cosmin Munteanu, Joel E. Fischer, Philip R. Doyle, and Fofish Kaye. 2020. CUI@CSCW: Collaborating through Conversational User Interfaces. In Conference Companion Publication of the 2020 on Computer Supported Cooperative Work and Social Computing. Association for Computing Machinery, New York, NY, USA. https://doi.org/10.1145/3406865. 3418587

[9] Steven R. Rick, Aaron Paul Goldberg, and Nadir Weibel. 2019. SleepBot: Encouraging Sleep Hygiene Using an Intelligent Chatbot. In Proceedings of the 24th International Conference on Intelligent User Interfaces: Companion (Marina del Ray, California) (IUI '19). Association for Computing Machinery, New York, NY, USA, 107-108. https://doi.org/10.1145/3308557.3308712 